\title{
Correlation of selected stress associated factors with vitamin $D$ deficiency in Jordanian men and
} women

\author{
Mahmoud S Abu-Samak' \\ Mohannad Eid AbuRuz ${ }^{2}$ \\ Rami Masa'Deh ${ }^{2}$ \\ Rula Khuzai ${ }^{2}$ \\ Samiha Jarrah ${ }^{2}$
}

'Department of Clinical Pharmacy and Therapeutics, Applied Science Private University, Amman, Jordan; ${ }^{2}$ Department of Clinical Nursing, School of Nursing, Applied Science Private University, Amman, Jordan
Correspondence: Mahmoud S Abu-Samak Department of Clinical Pharmacy and Therapeutics, Applied Science Private University, PO Box 142 Shafa Badran,

Amman II931, Jordan

Tel +96 2797098920

Email m_abusmak@asu.edu.jo
This article was published in the following Dove Press journal: International Journal of General Medicine

\begin{abstract}
Background: To identify stress associated factors for vitamin D deficiency (VDD) in healthy Jordanian people based on serum 25(OH)D levels.

Design: Prospective cohort study.

Methods: Three hundred and seventy-one Jordanian men and women aged 17-52 years, who were identified as VD deficient $25(\mathrm{OH}) \mathrm{D}<30 \mathrm{ng} / \mathrm{mL}$, were eligible to participate in the study. Serum vitamin $25(\mathrm{OH})$ D was measured using chemiluminescent immunoassay. Cortisol, parathyroid hormone, calcium, phosphate, fasting lipid profile, and blood glucose were also analyzed. Questionnaires were used to collect lifestyles parameters. Anthropometric parameters including: body mass index (BMI), waist (W) and hip (H) circumferences, W/H ratio (WHR) were also calculated.
\end{abstract}

Results: The vast majority (91\%) of the participants had vitamin D deficiency $(25-(\mathrm{OH})$ $\mathrm{D}<30 \mathrm{ng} / \mathrm{mL}$ ). Positive correlations were observed between vitamin D deficiency and the following anthropometric parameters in all study sample; gender $(P=0.010)$, height $(P=0.22)$, height/hip ratio $(P=0.015)$ and waist/hip ratio $(P=0.013)$. Lifestyle parameters that indicated very weak positive correlations with VDD were number of family members $(P=0.011)$ and insufficient exposure to sunlight $(P=0.023)$. The following clinical parameters showed weak or very weak correlations with VDD; serum cortisol $(r=0.318)$, low density lipoprotein $(r=0.246)$ and total cholesterol $(r=0.133)$. Skin color and water pipe tobacco smoking were added to the multivariable stepwise regression analyses as they have been weakly correlated with VDD. These predictors together explained only $12.2 \%$ of the variance in serum cortisol levels in the VDD study sample.

Conclusion: A weak positive association between VDD and elevated serum cortisol was observed in this study. Subcutaneous changes may be involved in that association but further studies are needed to clarify a potential role for adrenocorticotropic hormone (ACTH).

Keywords: Vitamin D deficiency, stress, cortisol, smoking, obesity

\section{Introduction}

The prevalence of vitamin D deficiency (VDD) has increased dramatically in Mediterranean countries as seen in Jordan ${ }^{1}$ Insufficient exposure to sunlight, as a leading cause of VDD, lacking of dietary sources, and malabsorption of the vitamin remain the most relevant factors. ${ }^{2}$ Nevertheless, several studies have shown that the prevalence of VDD has increased dramatically in the Middle Eastern populations despite abundant sunshine. ${ }^{3}$ Accordingly, main causes of VDD as well as their contributing factors are still not clear among Mediterranean populations including Jordanians. 
Allostatic load is an inability of the body's systems to accommodate adequately stress challenge due to chronic stressThis accompanies the modern lifestyle and impairs normal levels of stress mediators including cortisol (CORT) ${ }^{4}$ Therefore elevated CORT levels reflect decreased body's ability to counteract consequences of chronic stress, ${ }^{5,6}$ and to support quality of life. ${ }^{7}$ Accordingly, fluctuating blood levels of CORT have been correlated with certain individual's behaviors such as heavy cigarettes smoking, ${ }^{8}$ heavy coffee consumption, ${ }^{9}$ sleep deprivation, ${ }^{10}$ overweight, ${ }^{11,12}$ and hyperlipidemaia. ${ }^{13}$ Subsequently, some recent studies have focused on the association between VDD and lifestyle stressors. For example, significant inverse correlation has been observed between serum 25 (OH)D and postpartum allostatic stress. ${ }^{14}$ Similar observations were also noted between CORT and 1, 25-(OH) 2D3 (VD3) levels in preeclampsia (PE) patients. ${ }^{15}$ Furthermore, glucocorticoids (GC) administration lowered VD3 synthesis in PE-induced rats. ${ }^{15}$ However, clinical studies that correlated VDD with cortisol or stress associated factors were inconsistent. VDD was positively correlated with caffeine consumption habits in healthy male Korean subjects compared to their peers who did not consume caffeine at all. ${ }^{16}$ Conversely, a recent study conducted in Saudi Arabia excluded coffee consumption as a contributing factor for VDD. ${ }^{17}$ The relationship between VDD and cigarette smoking is also controversial. ${ }^{18-20}$ Finally, although prior studies have shown a positive relationship between VDD and obesity biomarkers. ${ }^{21-23}$ some of these biomarkers, including waist, hip, weight and body mass index (BMI), are still controversial in terms of the association degree with VDD particularly in relation to lifestyle stressors. Therefore, the purpose of this study was to assess the association between selected lifestyle stressors and the severity of VDD in healthy Jordanians.

\section{Subjects and methods}

\section{Research design and participants}

This was a prospective observational cohort study carried out at the Applied Science Private University (ASU), Amman, Jordan during the period from October 2015 to May 2017. To avoid some anticipated variations in the study sample, only male and female Jordanian ASU students and employees who live in Amman participated in the study. Anthropometric data of the participants were measured by group of research assistants. Research assistants filled out a questionnaire including anthropometric and lifestyle habits. That was through a face-to-face interview with each participant in this study on the day of blood sample collection. The total number participants who were approached to participate in the study was 407 , among which 36 were excluded because their VD levels were within normal values $(\geq 30 \mathrm{ng} / \mathrm{mL}){ }^{25}$ The same criteria for medical diagnosis of VDD are widely adopted in clinical diagnostics and trials. The remaining 371 participants composed the final sample that included in the analyses as shown in the schematic diagram of the study design (Figure 1).

\section{Ethical considerations}

This study was performed using a protocol no. DRGS2014-2015-165, approved by the ASU ethics committee for the protection of human subjects. The study was conducted in accordance with the Helsinki Declaration. All participants were provided with an information sheet, which contained details of the experimental protocol. Participants fully understood the purpose of the study as well as the risks involved. Participants were informed of being free to withdraw from the investigation at any stage. All participants provided written informed consent prior to commencement of the study and were asked to complete a health screening questionnaire prior to their participation in the study. For the participants under the age of 18 ( 2 students) written informed consent has been obtained from the student's guardian so that theses 2 students were able to participate in this study. This was acceptable and approved as an additional annex by the ethics committee according to protocol no. (DRGS 2014-2015-165).

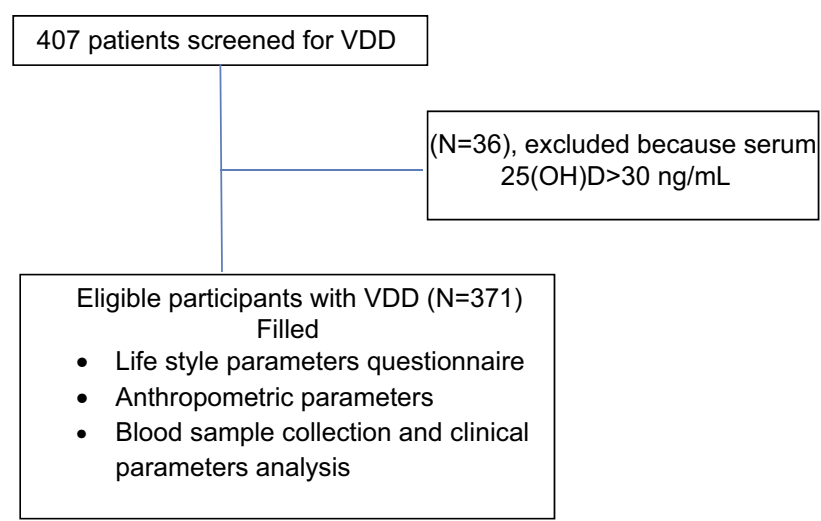

Figure I Schematic diagram of the study design. Abbreviation:VDD, vitamin $\mathrm{D}$ deficiency. 


\section{Data collection or measurement}

Anthropometric data included weight $(\mathrm{Wt})$, height $(\mathrm{Ht})$, BMI, waist (W) circumference, hip circumference (H), W/ $\mathrm{H}$ ratio (WHR), Ht/W ratio (HtWR) were collected following standard procedures. ${ }^{21,24}$ Age, gender, marital status, lifestyle data and clinical status of the participant included information on physical activity, cigarette or water-pipe tobacco smoking (WPTS), morning sun exposure, night sleep period, coffee and tea beverages consumption, family number, living alone or with family, number of family members were collected using a structured questionnaire.

\section{Sample size}

We assumed $95 \%$ confidence and margin of error $5 \%$. The number of ASU community was approximately 7,000 subjects including employees and students. Accordingly, 370 participants were required for this study. The same method of calculation has been used in a previous study conducted on Jordanian women with VDD in ASU 25 using research advisor's calculator Furthermore, the total number of participants for this study was in accordance with the number of participants recruited in similar recent randomized controlled trials involving females with VDD. ${ }^{25}$

\section{Clinical parameters assays Serum $25(\mathrm{OH}) \mathrm{D}$ assay}

Serum 25OHD levels were measured using chemiluminescent immunoassay technology by LIAISON $^{\circledR}$ 25hydroxyvitamin D Assay (DiaSorin, Stillwater, MN, USA). Specific antibody to VD was used for coating magnetic particles (solid phase) and VD was linked to an isoluminol derivative. Its lower limit of assay was approximately $(4 \mathrm{ng} / \mathrm{mL})$, and its intra- and interassay coefficients of variation were $5 \%$ and $8.2 \%$, respectively. The assay has a $100 \%$ cross-reactivity with both metabolites of 25 $(\mathrm{OH}) \mathrm{D}$ namely, 25(OH)D2 and 25(OH)D3 and thus measures total serum $25(\mathrm{OH}) \mathrm{D}$ content.

\section{Serum assays}

Serum CORT levels were measured using an ELISA, EIA1887 (DRG International, Inc., NJ, USA). The limits of detection of this assay were from $0-800 \mathrm{ng} / \mathrm{mL}$ with sensitivity $=2.5 \mathrm{ng} / \mathrm{mL}(6.0 \mathrm{nmo} / \mathrm{L})$ at a $95 \%$ confidence limit.

\section{Serum parathyroid hormone (PTH) assay}

The serum PTH levels were measured using PTH Intact ELISA KIT (DRG International) using Rayto RT2100C Microplate reader. It is a two-site ELISA for the measurements of PTH. The normal range of PTH ranged from $9-90 \mathrm{pg} / \mathrm{mL}$ for serum. Sensitivity of the test was $1.57 \mathrm{pg} / \mathrm{mL}$ and it was capable of detecting very low concentration levels.

Serum calcium levels were measured using CALCIUM-ARSENAZO kit (BioSystems, Barcelona, Spain), calcium in the serum reacts with Arsenazo III forming a colored complex that is measured using spectrophotometry (RAL Analyzers ClimaPlus, Barcelona, Spain). Normal serum calcium levels $8.6-10.3 \mathrm{mg} / \mathrm{dL}$, detection limit $=0.2 \mathrm{mg} / \mathrm{dL}$. Serum PO4 levels were measured using Phosphorus Phosphomolybdate/UV kit (BioSystems) using spectrophotometry (RAL Analyzers ClimaPlus). The reference values for serum PO4 were $2.5-4.5 \mathrm{mg} / \mathrm{dL}$ and the detection limit was $0.13 \mathrm{mg} / \mathrm{dL}$.

\section{Statistical method}

The statistical analyses were performed using a statistical software package SPSS, version 21.0 for Windows (IBM Corporation, Armonk, NY, USA). We calculated frequencies as well as means (SD) of predicted VDD overall for each variable. The $P$-values were considered significant at $P<0.05$ and differences between study participants were presented. We calculated Pearson correlations between 25 $(\mathrm{OH}) \mathrm{D}$ and each one of three categories of parameters; lifestyle, anthropometric and clinical. We used multivariate stepwise regression analysis to identify independent predictors for serum cortisol levels after adjusting for participant characteristics. Normality of distribution for laboratory measurements was tested using the Kolmogorov-Smirnov test and added as a supplementary material (Figure S1). Although the data did not follow normal distribution $(P=0.001$ for serum $25(\mathrm{OH}) \mathrm{D})$, it was approximately close to the normal distribution because of large sample size of the study.

\section{Results}

The characteristics of the 371 subjects, aged between 17 and 52, with VDD are presented in Table 1. The mean BMI refers to simple overweight $(25.5 \pm 5.5) \mathrm{kg} / \mathrm{m}^{2}$. Means waist and hip circumferences were $(84.28+/ 13.4$ and 101.8 $\pm 14.1) \mathrm{cm}$ respectively. Table 1 also shows selected lifestyle parameters.

The mean 25(OH)D serum value was $12.2 \mathrm{ng} / \mathrm{mL}$ (SD $5.7 \mathrm{ng} / \mathrm{mL}$ ) which classified as vitamin D deficiency Table 2 . Calciotropic hormone (PTH), ionized calcium $(\mathrm{Ca}+2)$ and phosphate in addition to serum morning cortisol were within physiological limits. Elevated lipid profile parameters (TG, 
Table I Baseline descriptive statistics of the anthropometric and life style parameters, $(\mathrm{N}=37 \mathrm{I})$

\begin{tabular}{|l|l|l|}
\hline Parameter & Range & Mean ISD \\
\hline Anthropometric parameter & $17.0-52.0$ & $27.4 \pm 10.1$ \\
\hline Age (years) & $1.46-0.195$ & $1.7 \pm 0.01$ \\
Height (m) & $39.0-134.0$ & $69.7 \pm 15.3$ \\
Weight (kg) & $15.8-46.5$ & $25.3 \pm 5.6$ \\
Body mass index (BMI) & $0.37-0.13$ & $84.3 \pm 13.4$ \\
Waist (cm) & $0.42-1.53$ & $1.01 \pm 0.14$ \\
Hip cm & $0.48-2.06$ & $0.83 \pm 0.15$ \\
WHR & $1.0-0.40$ & $1.66 \pm 0.31 .5$ \\
HtHR & \multicolumn{2}{|l}{} \\
\hline Lifestyle parameter & $2-17$ & $6.4 \pm 2.4$ \\
\hline Family number & $0-10$ & $1.2 \pm 1.4$ \\
Coffee consumption (100 mL/day) & $0-10$ & $1.3 \pm 1.3$ \\
Tea consumption/day (100 mL/day) & $0-16$ & $2.8 \pm 2.6$ \\
Mobile using (hours/day) & $0.25-5$ & $1.4 \pm 0.6$ \\
Water (liter/day) &
\end{tabular}

Abbreviations: $\mathrm{HT}$, height; $\mathrm{Wt}$, weight; BMI, body mass index; $\mathrm{W}$, waist; $\mathrm{H}$, hip; WHR, waist/hip ratio; HtHR, height/hip ratio.

Table 2 Baseline descriptive statistics of the clinical parameters, $(\mathrm{N}=37 \mathrm{I})$

\begin{tabular}{|c|c|c|}
\hline Parameter & Range & Mean \pm SD \\
\hline VD (ng/mL) & $3.50-29.5$ & $12.3 \pm 5.7$ \\
\hline CORT (pg/mL) & $4.3-32.0$ & $12.9 \pm 4.5$ \\
\hline FBG $(\mathrm{mg} / \mathrm{dL})$ & $54.0-119$ & $88.9 \pm 15.7$ \\
\hline TG (mg/dl) & $59.0-271$ & $143.9 \pm 26.7$ \\
\hline TC (mg/dL) & $117.0-460$ & $270.7 \pm 43$ \\
\hline LDL (mg/dL) & $54.0-302$ & $153.5 \pm 22.9$ \\
\hline $\mathrm{HDL}(\mathrm{mg} / \mathrm{dL})$ & $18.0-96.0$ & $56.9 \pm 8.2$ \\
\hline PTH $(\mathrm{pg} / \mathrm{mL})$ & $9.21-46.2$ & $21.8 \pm 10.2$ \\
\hline Calcium (mg/dL) & $7.8-22.9$ & II $.8 \pm 2.4$ \\
\hline Phosphorus (mg/dL) & $3.2-23$ & $5.9 \pm 3.3$ \\
\hline
\end{tabular}

Abbreviations: VD, 25(OH)D; CORT, serum cortisol; FBG, fasting blood glucose; TG, triglycerides; TC, total cholesterol; HDL, high density lipoproteins; LDL, low density lipoproteins; PTH, parathyroid hormone.

LDL, HDL and TC) were noted as shown in baseline descriptive of the clinical parameters for all participants in the study $(\mathrm{N}=371)$. The majority of participants in this study were females $(72 \%)$. This is due to the fact that the percentage of females exceeds males in most faculties of the ASU community, particularly the School of Pharmacy. Several positive lifestyles were observed as a predominant percentages of participants in the study including adequate sleep hours during the night $(81.7 \%)$, morning sun exposure $(75.2 \%)$, nonsmokers $(89.8 \%)$ and living with their families $(72.8 \%)$. Other baseline frequencies and percentages of
Table 3 Baseline frequencies and percentages of some anthropometric and lifestyle parameters, $(\mathrm{N}=37 \mathrm{I})$

\begin{tabular}{|l|l|}
\hline Parameter & N (\%) \\
\hline $\begin{array}{c}\text { Gender } \\
\text { Male } \\
\text { Female }\end{array}$ & $\begin{array}{l}104(28.0) \\
267(72.0)\end{array}$ \\
\hline Regular exercise (3 times/week) & $159(42.9)$ \\
\hline Night sleep (6-8 hours/night) & $303(81.7)$ \\
\hline Morning Sun exposure (30 minutes daily) & $279(75.2)$ \\
\hline Cigarette smoking (yes) & $38(10.2)$ \\
\hline $\begin{array}{l}\text { Skin color } \\
\text { White } \\
\text { C-skin }\end{array}$ & $179(48.2)$ \\
Black & $176(47.4)$ \\
\hline Living with family (yes) & $27.3)$ \\
\hline
\end{tabular}

Note: Percentages reflects the positive frequency.

studied anthropometric and lifestyle parameters are presented in Table 3.

\section{Correlations of lifestyle, anthropometric and clinical parameters with the vitamin $\mathrm{D}$ deficiency (VDD)}

In addition to gender $(P=0.01)$, anthropometric parameters; Ht, WHR and HtHR showed very weak positive correlations with VDD $(P=0.022,0.013,0.015)$, $(\mathrm{R}=0.119,0.129,0.127)$ respectively (Table 4$)$. Table 5 shows the correlations of associated lifestyle stresses with vitamin $\mathrm{D}$ levels. An expected, a significant

Table 4 Correlations of anthropometric parameters with VDD in all subjects

\begin{tabular}{|l|l|l|l|}
\hline Parameter & R & T-test & P-value \\
\hline Gender & - & 2.588 & $0.010^{*}$ \\
Age & -0.046 & - & 0.377 \\
Weight & 0.033 & - & 0.524 \\
Height & 0.119 & - & $0.022^{*}$ \\
BMI & -0.030 & - & 0.570 \\
Waist & 0.030 & - & 0.563 \\
Hips & -0.088 & - & 0.090 \\
WHR & 0.129 & - & $0.013^{*}$ \\
HtHR & 0.127 & - & $0.015^{*}$ \\
\hline
\end{tabular}

Notes: Unpaired t-test is used to compare between values of means from study sample of men and women with VDD. ${ }^{*} p<0.05$.

Abbreviations: VDD, vitamin D deficiency; R, Pearson correlation test; Wt, weight; $\mathrm{Ht}$, height; BMI, body mass index; $W$, waist; $H$, hips; WHR, waist/hip ratio; HtHR, height/hip ratio. 
Table 5 Correlations of selected lifestyle associated stress parameters with VDD in all subjects

\begin{tabular}{|l|l|l|l|}
\hline Parameter & R & t-test & P-value \\
\hline Family number & -0.131 & - & $0.011^{*}$ \\
Coffee consumption & -0.091 & - & 0.078 \\
Tea consumption & 0.002 & - & 0.965 \\
Mobile use & 0.055 & - & 0.291 \\
Regular exercise & - & 1.782 & 0.076 \\
Night sleep & - & 0.112 & 0.911 \\
Morning sun exposure & - & -2.286 & $0.023^{*}$ \\
Cigarette smoking & - & -0.188 & 0.851 \\
Water-pipe tobacco smoking & - & 1.231 & 0.219 \\
\hline
\end{tabular}

Note: ${ }^{*} p<0.05$.

Abbreviations: VDD, vitamin D deficiency; R, Pearson correlation test; WPTS, water-pipe tobacco smoking.

negative correlation between vitamin $\mathrm{D}$ levels and exposure to the sunlight $(t=-2.286, P<0.05)$ was noted. The number of family members of the participant was negatively correlated with vitamin D levels $(r=-0.131$, $P<0.05)$ indicating that larger family numbers are associated with higher severity of VDD. Regarding clinical parameters correlations (Table 4), obvious positive correlation has observed between mean serum levels of stress hormone (cortisol) and severity of VDD in this study $(r=0.318, P<0.001)$. Otherwise, LDL-C and TC also showed very weak positive correlations with the severity of VDD ( $r=0.246$ and $r=-0.133)$ as listed in Table 6.

\section{Multivariate analysis}

Multiple liner regression (stepwise method) was conducted to identify multivariate associations that mediated an increase of serum CORT levels in study participants with VDD. Stepwise regression model of VDD, skin color, and WTS were significantly influenced by serum CORT

Table 6 Correlations of clinical parameters with VDD in all subjects

\begin{tabular}{|l|l|l|}
\hline Parameter & $\mathbf{R}$ & P-value \\
\hline CORT $(\mathrm{pg} / \mathrm{mL})$ & 0.318 & 0.000 \\
FBG $(\mathrm{mg} / \mathrm{dL})$ & -0.091 & 0.079 \\
TG $(\mathrm{mg} / \mathrm{dL})$ & 0.003 & 0.947 \\
TC $(\mathrm{mg} / \mathrm{dL})$ & -0.133 & 0.011 \\
LDL $(\mathrm{mg} / \mathrm{dL})$ & 0.246 & 0.000 \\
HDL $(\mathrm{mg} / \mathrm{dL})$ & 0.081 & 0.121 \\
\hline
\end{tabular}

Abbreviations: VDD, vitamin D deficiency; R, Pearson correlation test; CORT, cortisol; FBG, fasting blood glucose; TG, triglycerides; TC, total cholesterol; LDL, low density lipoprotein; HDL, high density lipoprotein.
$\left(\mathrm{R}=0.349, \mathrm{R}^{2}=0.122, P<0.0001\right)$. The three predictors together clarified approximately $12 \%$ of the variance in CORT levels in the study. No further predictive variables were identified (Table 7).

\section{Discussion}

This study showed that VDD is associated with morning serum cortisol levels. Although the positive association between VDD and CORT was quite weak, it can be considered as a potential link between VD status and stress level in youth period. To our knowledge this work is the first to describe VDD and CORT as a stress hormone in a representative sample of Jordanian university students and older adults from both genders, despite controversial results on an association of low VD levels with CORT overproduction. $^{25,26}$ To some extent our findings were similar to study results that showed a negative correlation between VD and CORT levels in 55 Italian athletes. $^{26,27}$ Further, GC may increases the risk of preeclampsia via diminishing $\mathrm{VD}^{15}$ The same association was studied in a reverse way where vitamin D3 supplements suppressed HPA-axis activity. ${ }^{27,28}$ Similarly, in small-scale study $(\mathrm{N}=15)$, daily VD supplementation may reduce cardiovascular disease risk factors including a decrease in $11 \beta$-HSD1 activity, as evidenced by the decrease in the CORT/cortisone ratio. ${ }^{28,29}$ A linear increase of inflammatory markers including CORT $(P=0.025)$ and decrease of VD levels $(P<0.001)$ was also found across the entire sample of major depressive disorder. ${ }^{29,30}$ Although literatures on ethnic variances have demonstrated divergent diurnal CORT rhythms for Caucasians and Latinos, the nature of the variances are inconsistent across studies. ${ }^{30-32}$ However, it seems that people with dark skin showed higher levels of CORT as a part of physiological responses to psychosocial stressors and health behaviors such as smoking. ${ }^{32-34}$ Consequently, our observations showed thatparticipants with higher skin color had obviously increased VDD. This inverse correlation between skin color and $25(\mathrm{OH}) \mathrm{D}$ levels

Table 7 The multivariate association between stresses associated factors and serum cortisol levels by using multiple linear regression (stepwise method)

\begin{tabular}{|l|l|l|l|l|}
\hline Parameter & B & $\mathbf{R}$ & $\mathbf{R}^{\mathbf{2}}$ & P-value \\
\hline VDD & 0.253 & & & \\
Skin color & 0.837 & & & \\
Water-pipe tobacco smoking & 1.158 & 0.349 & 0.122 & 0.000 \\
\hline
\end{tabular}

Abbreviations: VDD, vitamin $D$ deficiency; $R$, Pearson correlation test; $R^{2}$, regression; WPTS, water-pipe tobacco smoking. 
has previously been noted. ${ }^{34,35}$ Therefore we adopt a potential synergistic association between certain related factors of stress and skin color with the severity of VDD. It is well known that adrenocorticotropic hormone (ACTH) has intrinsic melanocyte-stimulating hormone (MSH) activity causing generalized hyperpigmentation as a clinical feature of adrenocortical insufficiency. Because of ACTH secretion is low in secondary adrenal insufficiency, hyperpigmentation does not occur. This can be linked because all of the hypothalamus-pituitary-adrenal (HPA) axis elements are expressed in the skin including ACTH. ${ }^{35,36}$ Accordingally, association of stress with darkening of the skin has taken particular attention in recent studies conducted on humans and animals. ${ }^{37,41}$ In humans, developed pigmentation was observed in response to a combination of ultraviolat radiation (UV) and low humidity stress to the epidermal barrier. ${ }^{37}$ In Mathematical modeling and empirical studies ${ }^{38}$ showed that the melanocyte master regulator, microphthalmia-associated transcription factor (MITF) serves to synchronize stress responses and pigmentation. This hypothesis was previously noted, where ACTH activated brown adipose tissue and influenced browning of white adipose tissue whereas corticosterone counteracts ACTH action. ${ }^{39}$ Surprisingly, increasing skin pigmentation following severe head trauma was observed in a case of a 67-year-old man. The patient's hormone study showed high levels of ACTH (978 pg/mL) with normal cortisol levels. $^{40}$

Finally, To understand the functional mechanisms of dynamic color in amphibians, injected ACTH used as a maximum stressor model, did not lead to a skinlightening response. ${ }^{41}$ Consequently, the same UV exposure produces less vitamin D in brown-skinned people compared to white-skinned. ${ }^{42}$

In recent decades, water-pipe tobacco smoking (WPTS) has become widely popular among Jordanians particularly in youth. Some previous studies have linked VDD with cigarette smoking. ${ }^{18,19}$ Remarkable changes were noted in rat offspring after exposure to tobacco during the lactation period including developed resistance to vitamin D in the adipocyte, HPA-axis dysfunction and visceral lipogenesis. ${ }^{36,43}$ An increase in alpha hydroxylase associated with significant reduction of VDR has also been noted in obese induced rats. ${ }^{44}$

Alternatively, some of anthropometric parameters including lipid profile and adiposity measures showed significant correlations with VDD. High prevalence of VDD observed in our sample appears to coexist with hyperlipidemia which is positively associated with stress and cortisol levels. The majority of recent studies suggest a negative relationship between VD status and LDL-c serum levels ${ }^{38,45}$ in healthy subjects ${ }^{39-41,46-48}$ and in patients. $^{42,49}$ In relation to stress, hyperlipidemia in cardiovascular disease patients has contributed to excessive CORT levels. ${ }^{43,44,50,51}$

Al-Dujaili et $\mathrm{al}^{29}$ reported that, in coronary artery disease (CAD), hyperlipidemia can be ameliorated under effect of VD supplementation via decreasing $11 \beta$-HSD1 activity. Metabolically, cholesterol is a precursor molecule for VD as well as CORT synthesis. The branching point in the metabolism is 7-cholesterol (7DHC) from which both VD and cholesterol are formed. ${ }^{52,53}$ Accordingly, some relevant research hypothesized a linkage between cholesterol, VD, and steroid hormones in some subclinical cases. ${ }^{45,54}$

VDD has recently been linked to obesity. ${ }^{46,55}$ Interestingly, a higher association between waist/hip ratio WHR and VDD observed in our study are consistent with some previous studies. ${ }^{41,46,47,56}$ Nevertheless, observations of some small-scale ${ }^{46,55}$ studies were partially inconsistent with our findings. In a large-scale study, Al-Daghri et $\mathrm{al}^{56}$ found that WHR was less significant than other anthropometric measures of obesity regarding the strength of association with VD status. However, the inverse correlation observed between VD levels with waist ${ }^{49,50,57,58}$ or hip $^{51,53,59,60}$ circumferences in previous studies may result due to subcutaneously visceral adiposity alterations. ${ }^{39,46,54,61}$ Similar alterations were also noted in elderly Korean women. ${ }^{55,62}$

\section{Study limitations}

The major limitation of this study was that we did not measure serum ACTH levels to evaluate HPA axis and its relationship with VDD.

\section{Conclusion}

Overall, our observations confirm the association between the severity of VDD and serum CORT levels as a predictor of HPA axis. This association will be clarified in further studies in which we will assess the role of ACTH on vitamin $\mathrm{D}$ metabolism in the subcutaneous layer.

\section{Acknowledgments}

The authors are grateful to the Applied Science Private University (ASU), Amman, Jordan, for the full financial support granted for this research project (Grant No.DRGS2014-2015-165). 


\section{Disclosure}

The authors report no conflicts of interest in this work.

\section{References}

1. Al-Horani H, Abu Dayyih W, Mallah E, et al. Nationality, gender, age, and body mass index influences on vitamin D concentration among elderly patients and Young Iraqi and Jordanian in Jordan. Biochem Res Int. 2016;2016:8920503. doi:10.1155/2016/7108261

2. Nichols EK, Khatib IM, Aburto NJ, et al. Vitamin D status and associated factors of deficiency among Jordanian children of preschool age. Eur J Clin Nutr. 2015;69(1):90-95. doi:10.1038/ejen.2014.142

3. Fields J, Trivedi NJ, Horton E, Mechanick JI. Vitamin D in the Persian Gulf: integrative physiology and socioeconomic factors. Curr Osteoporos Rep. 2011;9(4):243-250. doi:10.1007/s11914-011-0071-2

4. Bruce S. McEwen. Stressed or stressed out: what is the difference? J Psychiatry Neurosci. 2005;30(5):315-318.

5. Yirmiya K, Djalovski A, Motsan S, Zagoory-Sharon O, Feldman R. Stress and immune biomarkers interact with parenting behavior to shape anxiety symptoms in trauma-exposed youth. Psychoneuroendocrinology. 2018;98:153-160. doi:10.1016/j.psyneuen.2018.08.016

6. Doan SN, DeYoung G, Fuller-Rowell TE, Liu C, Meyer J. Investigating relations among stress, sleep and nail cortisol and DHEA. Stress. 2018;21(2):188-193. doi:10.1080/10253890.2018.1429398

7. Manoy P, Yuktanandana P, Tanavalee A, et al. Vitamin D supplementation improves quality of life and physical performance in osteoarthritis patients. Nutrients. 2017;9(8). doi:10.3390/nu9080799

8. Reddy SP, Prasad MG, RadhaKrishna AN, et al. Correlation between salivary cortisol levels and dental anxiety in children of smokers and nonsmokers. Eur $J$ Dent. 2017;11(2):192-195. doi:10.4103/ejd. ejd_171_16

9. Gavrieli A, Yannakoulia M, Fragopoulou E, et al. Caffeinated coffee does not acutely affect energy intake, appetite, or inflammation but prevents serum cortisol concentrations from falling in healthy men. J Nutr. 2011;141(4):703-707. doi:10.3945/jn.110.137323

10. Abu-Samak MS, Mohammad BA, Abu-Taha MI, Hasoun LZ, Awwad SH. Associations between sleep deprivation and salivary testosterone levels in male university students: a prospective cohort study. $A m$ J Mens Health. 2018;12(2):411-419. doi:10.1177/1557988317735412

11. Jackson SE, Steptoe A. Obesity, perceived weight discrimination, and hair cortisol: a population-based study. Psychoneuroendocrinology. 2018;98:67-73. doi:10.1016/j.psyneuen.2018.08.018

12. Nair R, Maseeh A. Vitamin D: the "sunshine" vitamin. J Pharmacol Pharmacother. 2012;3(2):118-126. doi:10.4103/0976-500X.95506

13. Wang TJ, Pencina MJ, Booth SL, et al. Vitamin D deficiency and risk of cardiovascular disease. Circulation. 2008;117(4):503-511. doi:10.1161/CIRCULATIONAHA.107.706127

14. Accortt EE, Mirocha J, Dunkel Schetter C, Hobel CJ. Adverse perinatal outcomes and postpartum multi-systemic dysregulation: adding vitamin D deficiency to the allostatic load index. Matern Child Health J. 2017;21(3):398-406. doi:10.1007/s10995-016-2226-3

15. Zhang D, Zeng J, Miao X, et al. Glucocorticoid exposure induces preeclampsia via dampening 1,25-dihydroxyvitamin D3. Hypertens Res. 2018;41(2):104-111. doi:10.1038/hr.2017.98

16. Lim HS, Lee HH, Byun DW, et al. Serum vitamin D level related to coffee consumption in Korean young adults using the 5th Korea National Health and Nutrition Examination Survey. $J$ Bone Metab. 2017;24(4):229-233. doi:10.11005/jbm.2017.24.4.229

17. Al-Raddadi R, Bahijri S, Borai A, AlRaddadi Z. Prevalence of lifestyle practices that might affect bone health in relation to vitamin D status among female Saudi adolescents. Nutrition. 2018;45:108-113. doi:10.1016/j.nut.2017.07.015
18. Knapik JJ, Bedno SA. Epidemiological evidence and possible mechanisms for the association between cigarette smoking and injuries (Part 1). J Spec Oper Med. 2018;18(1):108-112.

19. Wu X, Cheng J, Yang K. Vitamin D-related gene polymorphisms, plasma 25-hydroxy-vitamin d, cigarette smoke and non-small cell lung cancer (NSCLC) risk. Int J Mol Sci. 2016;17(10). doi:10.3390/ijms17101597

20. Banihosseini SZ, Baheiraei A, Shirzad N, Heshmat R, Mohsenifar A. The effect of cigarette smoke exposure on vitamin $\mathrm{D}$ level and biochemical parameters of mothers and neonates. $J$ Diabetes Metab Disord. 2013;12(1):19. doi:10.1186/2251-6581-12-19

21. Sousa-Santos AR, Afonso C, Santos A. The association between 25 $(\mathrm{OH}) \mathrm{D}$ levels, frailty status and obesity indices in older adults. PLoS One. 2018;13(8):e0198650. doi:10.1371/journal.pone.0198650

22. Kim SH, Oh JE. The factors associated with Vitamin D deficiency in community dwelling elderly in Korea. Nutr Res Pract. 2018;12 (5):387-395. doi:10.4162/nrp.2018.12.5.387

23. Fu J, Han L, Zhao Y, et al. Vitamin D levels are associated with metabolic syndrome in adolescents and young adults: the BCAMS study. Clin Nutr. 2018;S0261-S5614(18):32435-X.

24. Stewart M-J, Mike O, Tim D, Ridder H. International Standards for Anthropometric assessment/Arthur Stewart, Michael Marfell-Jones, Timothy Olds, and Hans De Ridder. Lower Hutt, New Zealand: International Society for the Advancement of Kinanthropometry; 2011.

25. Al-Shaer AH, Abu-Samak MS, Hasoun LZ, Mohammad BA, Basheti IA. Assessing the effect of omega-3 fatty acid combined with vitamin D3 versus vitamin D3 alone on estradiol levels: a randomized, placebo-controlled trial in females with vitamin D deficiency. Clin Pharmacol. 2019;11:25-37. Published February 2019, 4. doi:10.2147/CPAA.S182927

26. Muscogiuri G, Altieri B, Penna-Martinez M, Badenhoop K. Focus on vitamin D and the adrenal gland. Horm Metab Res. 2015;47 (4):239-246. doi:10.1055/s-0034-1396893

27. Lombardi G, Vitale JA, Logoluso S, et al. Circannual rhythm of plasmatic vitamin D levels and the association with markers of psychophysical stress in a cohort of Italian professional soccer players. Chronobiol Int. 2017;34(4):471-479. doi:10.1080/ 07420528.2017.1297820

28. Rolf L, Damoiseaux J, Huitinga I, et al. Stress-axis regulation by vitamin D3 in multiple sclerosis. Front Neurol. 2018;9:263. doi:10.3389/ fneur.2018.00263

29. A1-Dujaili EA, Munir N, Iniesta RR. Effect of vitamin D supplementation on cardiovascular disease risk factors and exercise performance in healthy participants: a randomized placebo-controlled preliminary study. Ther Adv Endocrinol Metab. 2016;7(4):153-165. doi:10.1177/2042018816653357

30. Verduijn J, Milaneschi Y, Schoevers RA, et al. Pathophysiology of major depressive disorder: mechanisms involved in etiology are not associated with clinical progression. Transl Psychiatry. 2015;5:e649. doi:10.1038/tp.2015.137

31. Suglia SF, Staudenmayer J, Cohen S, et al. Cumulative stress and cortisol disruption among black and hispanic pregnant women in an urban cohort. Psychol Trauma. 2010;2(4):326-334. doi:10.1037/a0018953

32. Hajat A, Diez-Roux A, Franklin TG, et al. Socioeconomic and race/ ethnic differences in daily salivary cortisol profiles: the multi-ethnic study of atherosclerosis. Psychoneuroendocrinology. 2010;35 (6):932-943. doi:10.1016/j.psyneuen.2009.12.009

33. Cuevas AG, Dawson BA, Williams DR. Race and skin color in latino health: an analytic review. Am J Public Health. 2016;106 (12):2131-2136. doi:10.2105/AJPH.2016.303452

34. Wassink J 1, Perreira KM, Harris KM. Beyond race/ethnicity: skin color and cardiometabolic health among blacks and hispanics in the United States. J Immigr Minor Health. 2017;19(5):1018-10A26. doi:10.1007/s10903-016-0495-y 
35. Godar DE, Pope SJ, Grant WB, Holick MF. Solar UV doses of adult Americans and vitamin D (3) production. Dermatoendocrinol. 2011;3 (4):243-250. doi:10.4161/derm.3.4.15292

36. Novaes Soares P, Silva Tavares Rodrigues V, Cherem PT, et al. Cigarette smoke during breastfeeding in rats changes glucocorticoid and Vitamin D status in obese adult offspring. Int J Mol Sci. 2018;19(10). doi:10.3390/ ijms 19103084

37. Elias PM, Menon G, Wetzel BK, Williams JJ. Evidence that stress to the epidermal barrier influenced the development of pigmentation in humans. Pigment Cell Melanoma Res. 2009;22(4):420-434. doi:10.1111/j.1755-148X.2009.00588.x

38. Malcov-Brog H, Alpert A, Golan T, et al. UV-protection timer controls linkage between stress and pigmentation skin protection systems. Mol Cell. 2018;72(3):444-456. doi:10.1016/j. molcel.2018.09.022

39. van Den Beukel JC, Grefhorst A, Quarta C, et al. Direct activating effects of adrenocorticotropic hormone (ACTH) on brown adipose tissue are attenuated by corticosterone. FASEB J. 2014;28 (11):4857-4867. doi:10.1096/fj.14-254839

40. Katsenos C, Moukas M, Baka V, Kafkoula E, Androulaki D, Mandragos K. Increasing skin pigmentation following severe head trauma: all that glitters is not gold! Eur J Case Rep Intern Med. 2016;3(6):000464

41. Kindermann C, Narayan EJ, Wild F, Wild CH, Hero JM. The effect of stress and stress hormones on dynamic colour-change in a sexually dichromatic Australian frog. Comp Biochem Physiol A Mol Integr Physiol. 2013;165(2):223-227. doi:10.1016/j.cbpa.2013.03.011

42. Felton SJ, Cooke MS, Kift R, et al. Concurrent beneficial (vitamin $\mathrm{D}$ production) and hazardous (cutaneous DNA damage) impact of repeated low-level summer sunlight exposures. $\mathrm{Br} J$ Dermatol. 2016;175(6):1320-1328. doi:10.1111/bjd.14863

43. Soares PN, Rodrigues VST, Peixoto TC, et al. Cigarette smoke during breastfeeding in rats changes glucocorticoid and vitamin D status in obese adult offspring. Int J Mol Sci. 2018;19(10):3084. doi:10.3390/ijms19103084

44. Conceicao EP, Moura EG, Manhaes AC, et al. Calcium reduces vitamin $\mathrm{D}$ and glucocorticoid receptors in the visceral fat of obese male rats. J Endocrinol. 2016;230:263-274. doi:10.1530/JOE-16-0041

45. Chiang JM, Stanczyk FZ, Kanaya AM. Vitamin D levels, body composition, and metabolic factors in asian indians: results from the metabolic syndrome and atherosclerosis in South Asians Living in America pilot study. Ann Nutr Metab. 2018;72(3):223-230. doi: $10.1159 / 000487272$

46. Pinkas J, Bojar I, Gujski M, et al. Serum lipid, vitamin D levels, and obesity in perimenopausal and postmenopausal women in non-manual employment. Med Sci Monit. 2017;23:5018-5026.

47. Roy A, Lakshmy R, Tarik M, et al. Independent association of severe vitamin $\mathrm{D}$ deficiency as a risk of acute myocardial infarction in Indians. Indian Heart J. 2015;67(1):27-32. doi:10.1016/j. ihj.2015.02.002

48. Faraji R, Sharami SH, Zahiri Z, et al. Evaluation of relation between anthropometric indices and vitamin $\mathrm{D}$ concentrations in women with polycystic ovarian syndrome. J Family Reprod Health. 2014;8 (3):123-129.
49. Teixeira JS, Bull Ferreira Campos A, Cordeiro A, Pereira SE, Saboya CJ, Ramalho A. Vitamin D nutritional status and its relationship with metabolic changes in adolescents and adults with severe obesity. Nutr Hosp. 2018;35(4):847-853. doi:10.20960/nh.1657

50. Nakhl S, Sleilaty G, El Samad S, et al. Association between vitamin $\mathrm{D}$ deficiency and lipid and non-lipid markers of cardiovascular diseases in the middle east region. Eur J Clin Nutr. 2018. doi:10.1038/ s41430-018-0280-1

51. Payne AH, Hales DB. Overview of steroidogenic enzymes in the pathway from cholesterol to active steroid hormones. Endocr Rev. 2004;25:947-970. doi:10.1210/er.2003-0030

52. Zhu W, Heil DP. Associations of vitamin D status with markers of metabolic health: A community-based study in Shanghai, China. Diabetes Metab Syndr. 2018;12(5):727-732. doi:10.1016/j. dsx.2018.04.010

53. Mintziori G, Georgiou T, Anagnostis P, et al. Could lipid profile be used as a marker of autonomous cortisol secretion in patients with adrenal incidentalomas? Horm Metab Res. 2018;50(7):551-555. doi:10.1055/a-0630-1397

54. Mousa A, Naderpoor N, Mpj DC, Scragg R, de Courten B. 25hydroxyvitamin $\mathrm{D}$ is associated with adiposity and cardiometabolic risk factors in a predominantly vitamin D-deficient and overweight/ obese but otherwise healthy cohort. J Steroid Biochem Mol Biol. 2017;173:258-264. doi:10.1016/j.jsbmb.2016.12.008

55. Sofi NY, Jain M, Kapil U, et al. Nutritional risk factors and status of serum 25(OH)D levels in patients with breast cancer: A case control study in India. J Steroid Biochem Mol Biol. 2018;175:55-59. doi:10.1016/j.jsbmb.2016.09.020

56. Al-Daghri NM, Sabico S, Al-Saleh Y, et al. Calculated adiposity and lipid indices in healthy Arab children as influenced by vitamin D status. J Clin Lipidol. 2016;10(4):775-781. doi:10.1016/j. jacl.2016.02.005

57. Kramkowska M, Grzelak T, Walczak M, et al. Relationship between deficiency of vitamin D and exponents of metabolic syndrome. Eur Rev Med Pharmacol Sci. 2015;19(12):2180-2187.

58. Al Asoom LI. The association of adiposity indices and plasma vitamin $\mathrm{D}$ in young females in Saudi Arabia. Int $J$ Endocrinol. 2016;2016:1215362. doi:10.1155/2016/1215362

59. Salehi S, Sadeghi F, Akhlaghi M, Hanifpour MA, Roshanzamir M. Vitamin D3-fortified milk did not affect glycemic control, lipid profile, and anthropometric measures in patients with type 2 diabetes, a triple-blind randomized clinical trial. Eur J Clin Nutr. 2018;72 (8):1083-1092. doi:10.1038/s41430-017-0062-1

60. Zhang Y, Zhang X, Wang F, et al. The relationship between obesity indices and serum vitamin $\mathrm{D}$ levels in Chinese adults from urban settings. Asia Pac J Clin Nutr. 2016;25(2):333-339. doi:10.6133/ apjen.2016.25.2.15

61. Cheng S, Massaro JM, Fox CS, et al. Adiposity, cardiometabolic risk, and vitamin D status: the framingham heart study. Diabetes. 2010;59 (1):242-248. doi:10.2337/db09-1011

62. Song BM, Rhee Y, Kim CO, et al. Urban-rural differences explain the association between serum 25-hydroxyvitamin D level and insulin resistance in Korea. Nutrients. 2014;6(12):5806-5818. doi:10.3390/ nu6125806 


\section{Supplementary material}

\begin{tabular}{|ll|r|}
\hline & & $\begin{array}{c}\text { Vitamin D 30 75 } \\
\mathrm{ng} / \mathrm{mL}\end{array}$ \\
\hline $\mathrm{N}$ & & 371 \\
Normal parameters ${ }^{\mathrm{a}, \mathrm{b}}$ & Mean & 12.2399 \\
& SD & 5.71713 \\
Most extreme differences & Absolute & 0.101 \\
& Positive & 0.101 \\
& Negative & $-.077-$ \\
Kolmogorov-Smirnov Z & & 1.939 \\
Asymp. Sig. (2-tailed) & & 0.001 \\
\hline
\end{tabular}

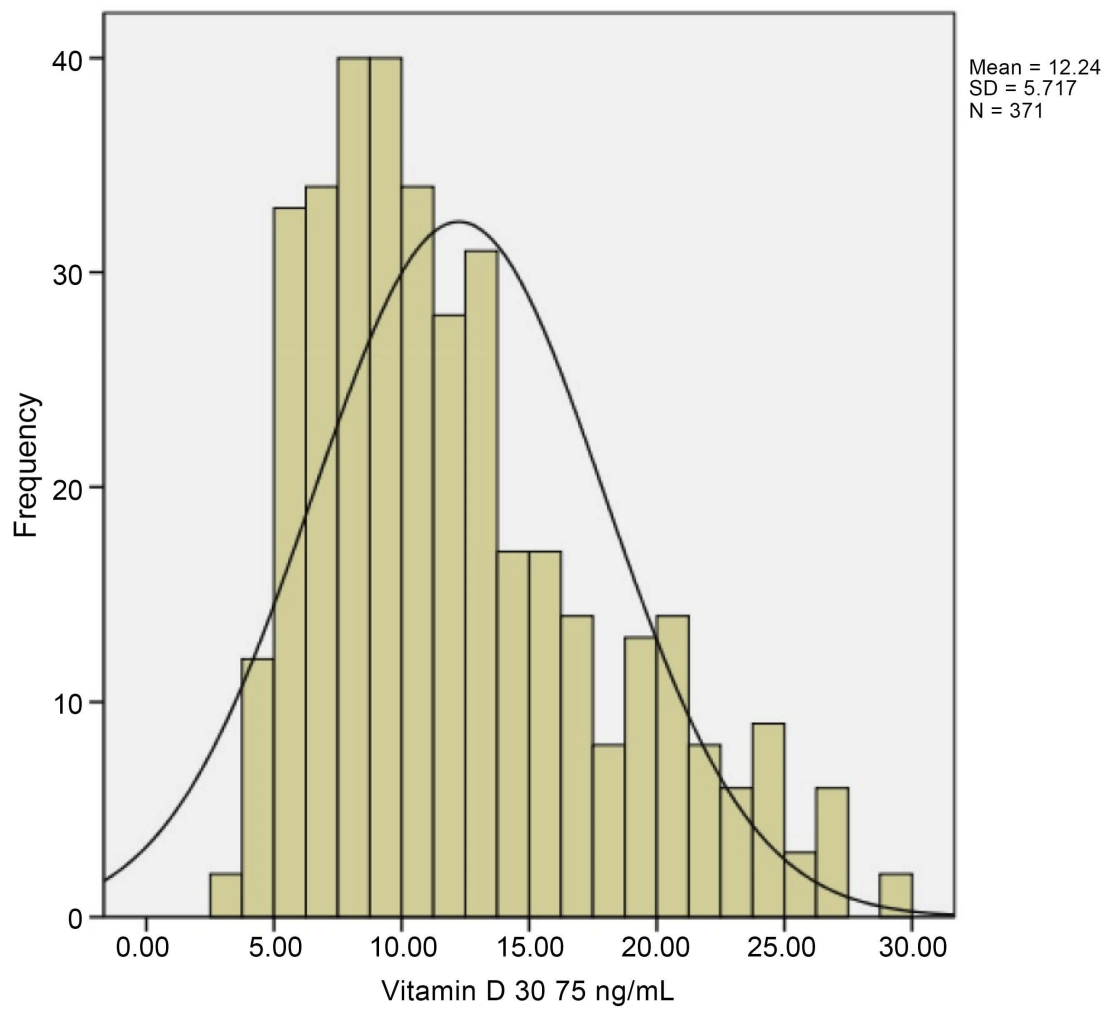

Figure SI One-sample Kolmogorov-Smirnov test.

Notes: ${ }^{\text {a }}$ Test distribution is normal. ${ }^{\text {b } C a l c u l a t e d ~ f r o m ~ d a t a . ~}$

International Journal of General Medicine

Dovepress

\section{Publish your work in this journal}

The International Journal of General Medicine is an international, peer-reviewed open-access journal that focuses on general and internal medicine, pathogenesis, epidemiology, diagnosis, monitoring and treatment protocols. The journal is characterized by the rapid reporting of reviews, original research and clinical studie across all disease areas. The manuscript management system is completely online and includes a very quick and fair peer-review system, which is all easy to use. Visit http://www.dovepress.com/ testimonials.php to read real quotes from published authors. 